\title{
On reproduction in red algae: further research needed at the molecular level
}

\author{
Pilar García-Jiménez and Rafael R. Robaina* \\ Departamento de Biología, Universidad de Las Palmas de Gran Canaria, Las Palmas de Gran Canaria, Spain
}

Edited by:

Elena M. Kramer, Harvard

University, USA

Reviewed by:

Madelaine E. Bartlett, University of

Massachusetts Amherst, USA

Yoji Nakamura, National Research

Institute of Fisheries Science, Japan

\section{*Correspondence:}

Rafael R. Robaina, Departamento

de Biología, Universidad de Las

Palmas de Gran Canaria, 35017 Las

Palmas de Gran Canaria, Canary

Islands, Spain

e-mail: rafael.robaina@ulpgc.es
Multicellular red algae (Rhodophyta) have some of the most complex life cycles known in living organisms. Economically valuable seaweeds, such as phycocolloid producers, have a triphasic (gametophyte, carposporophyte, and tetrasporophyte) life cycle, not to mention the intricate alternation of generations in the edible "sushi-alga" nori. It is a well-known fact that reproductive processes are controlled by one or more abiotic factor(s), including day length, light quality, temperature, and nutrients. Likewise, endogenous chemical factors such as plant growth regulators have been reported to affect reproductive events in some red seaweeds. Still, in the genomic era and given the high throughput techniques at our disposal, our knowledge about the endogenous molecular machinery lags far behind that of higher plants. Any potential effective control of the reproductive process will entail revisiting most of these results and facts to answer basic biological questions as yet unresolved. Recent results have shed light on the involvement of several genes in red alga reproductive events. In addition, a working species characterized by a simple filamentous architecture, easy cultivation, and accessible genomes may also facilitate our task.

Keywords: Rhodophyta, seaweeds, reproduction, light, hormones, photoreceptors, signaling

\section{RHODOPHYTA AND REPRODUCTION. MERGING APPLIED AND FUNDAMENTAL KNOWLEDGE INTEREST}

As recently reviewed (Rebours et al., 2014), the seaweed industry produces some 10 billion US\$. Among the species exploited, the red seaweeds (Rhodophyta) Eucheuma/Kappaphycus, Porphyra, and Gracilaria occupy a leading position (Kappaphycus alone generates 1.3 billion US\$ while the nori market is estimated at 1.5 billion US\$). Nevertheless, this industry mostly relies on the exploitation of natural populations or primitive aquaculture methods, its expansion being restricted by the lack of technical and knowledge advances. An example of this can be seen in the absence of control of reproductive traits that would allow us to increase production, strain selection and breeding, a major step forward which has been achieved in land plant culture.

Rhodophyta are classified as Archaeplastida, along with glaucophytes and Viridiplantae (land plants and green algae) from which they diverge 1,500 Mya (Yoon et al., 2004). Like other algal groups, red algae comprise a myriad of species with different types of body architecture, ranging from the unicellular and filamentous to the blade or pseudo-parenchymatous as the most complex, particularly in the case of industrially valuable seaweeds (Cole and Sheath, 1995). Their extremely complex life cycles include the transition from unicellularity to complex multicellular bodies, the underlying molecular bases of which are virtually unknown. The diploid "conchocelis" and the meioticderived conchospores sustain the industry of "sushi," since the tiny unicellular meiospore, the conchospore, grows and develops into the haploid leafy thallus, which is the edible phase (Drew, 1949, 1954).

Other economically valuable red algae, such as the producers of the phycocolloids agar or carrageen, have a trigenetic life cycle in which the haploid unicellular meiotic tetraspores germinate to produce both a male and a female multicellular gametophyte thalli (Cole and Sheath, 1995). Fertilization occurs when a spermatium fertilizes a carpogonium on the female gametophyte. The fertilized carpogonium develops into a structure called the cystocarp (diploid) after complex cell differentiation events, leading to the accumulation of mitotic diploid carpospores. Eventually, diploid carpospores are released and develop into tetrasporophytes that produce the meiotic tetraspores (Figure 1).

Recent reviews continue to focus on a plethora of external factors that control algal reproduction such as light (intensity, quality, photoperiod), temperature, season, nutrients (be they inorganic or organic), biotic factors (extracellular algal products, bacterial association, animal grazing), osmotic stress, $\mathrm{pH}$ of the medium, wave motion and mechanical shock, pollution, and radiations, and the bulk of knowledge accumulated as to the particular conditions on which these external factors exert their control (Dring, 1988; Bornette and Puijalon, 2011; Agrawal, 2012).

Light and temperature are managed effectively to run the intensive cultivation system of Porphyra, but there is a general 


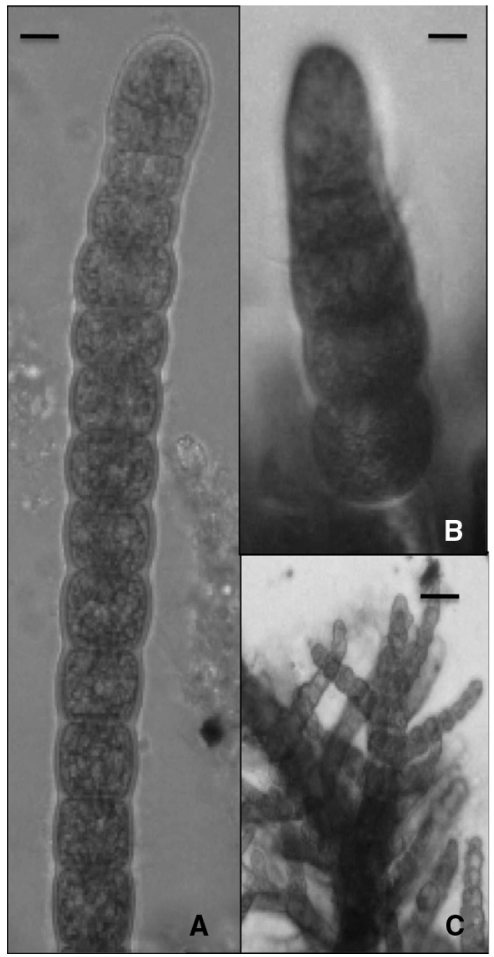

B

TETRASPORANGIA

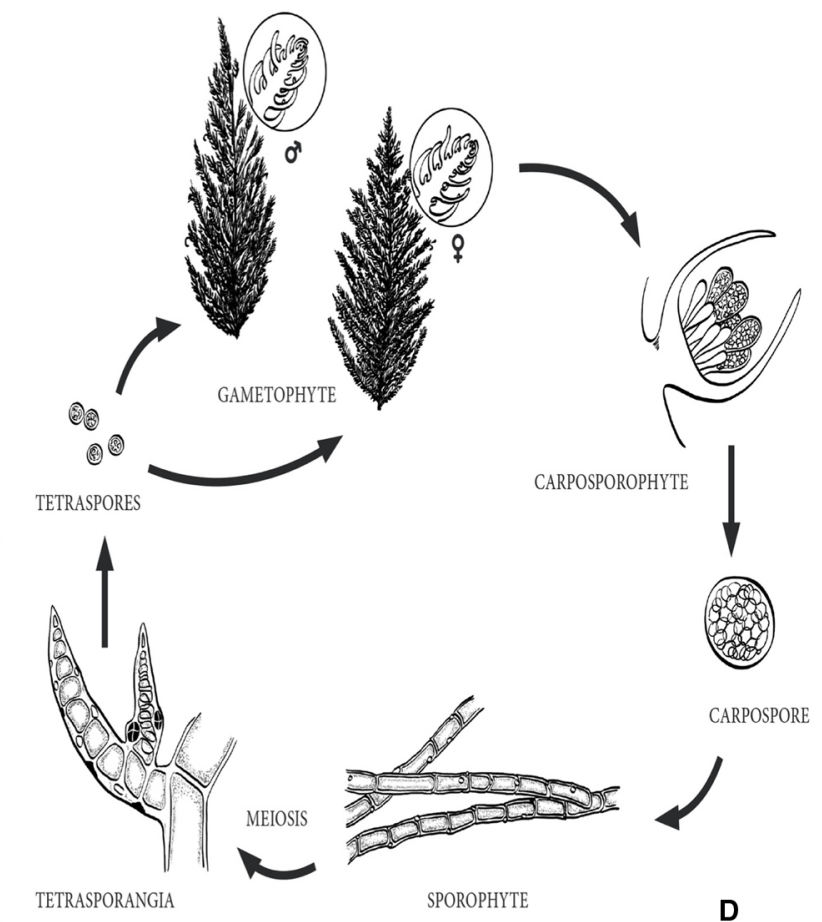

FIGURE 1 | (A) Apical portion of a sporophyte branch of Bonnemaisonia hamifera, scale bar $=120 \mu \mathrm{m}$. (B) Putative gametophyte sporeling, scale bar $=25 \mu \mathrm{m}$. (C) Apex of a immature gametophytic thalli, scale bar $=100 \mu \mathrm{m}$. (D) Diagram of putative trigenetic life cycle in the red alga

consensus that increasing our knowledge of the underlying molecular basis of cell growth, development and reproduction in this species, and in economical important seaweeds in general, will improve aquaculture practices (Sahoo et al., 2002; Nakamura et al., 2013).

As we will see below, the same situation occurs when the effect of plant hormones on seaweed reproduction is considered, although some advances at the molecular level have been made on the involvement of certain genes. Almost nothing is known about how the external signals are translated into the molecular mechanisms known to underlie any developmental or reproductive event comprising cell growth and differentiation. Whilst this task was addressed for land plants some time ago, in the genomic era and given the high throughput techniques at our disposal, our knowledge regarding algae in general, and seaweeds in particular, lags far behind that of higher plants and animals. Let us therefore review what is already known about plants and should be revisited in red algae to unveil the secrets of what, no doubt, is also operating at the molecular level to control reproduction.

\section{REPRODUCTION GENES IN RED ALGAE. DISPARATE MODEL SPECIES AND APPROACHES}

As seen in the most recent bibliographic reports, and is evident in this special edition, major advances are taking place in the brown alga since the adoption of Ectocarpus siliculosus as the model reproductive event. algae.
Bonnemaisonia comprising the gametophytes (haploids), the so-called carposporophyte that develops on the female gametophyte after fertilization, and the sporophyte (diploid) (adapted from B. geniculata in Shevlin and Polanshek, 1978. Not a scale).

species and the generalized use of high throughput techniques. This includes key genes in the life cycle transition, developmental pattern, etc. (Peters et al., 2004; Cock et al., 2010; Coelho et al., 2011; Le Bail et al., 2011; Arun et al., 2013). If E. siliculosus was chosen mainly because of the particular taxonomic position of brown algae and the evolutionary lineage-related information that could be retrieved from it (Peters et al., 2004), in red algae, no general consensus has been reached as to either the model species or technical approaches and strategies. Consequently, limited advances have been achieved to date, particularly regarding the

Porphyra species (Rhodophyta, Bangiophyceae)—or rather Porphyra/Pyropia species, as several species has been reassigned as Pyropia (Sutherland et al., 2011) - have been proposed as model species, perhaps because of their economic value. The genome and symbiont-free genome have been sequenced (Chan et al., 2012; Nakamura et al., 2013), and 1\% of the genes $(10,327$ total genes predicted) were annotated as related to reproduction in $P$. yezoensis, using the estimation provided by GO Slim in the Blast2Go software (Nakamura et al., 2013). Therefore, this genomic approach always faces a serious constraint, since these genes are commonly assigned to putative biological processes and functions based on the information available for other organisms, that may simply lack genes and functions related to important life cycle or reproduction events in red 
Table 1 | An overview of the complex light sensing-plant hormones interaction, highlighting the key molecular factors implicated.

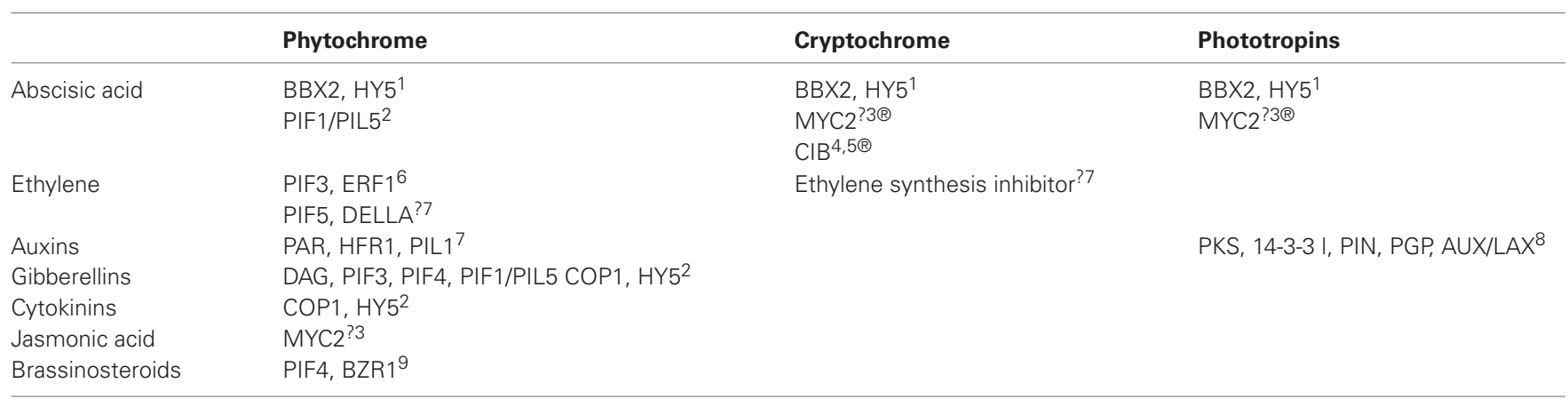

All of the information comes from higher plants, mostly Arabidopsis thaliana. Prominent role are played by transcription factors (TF) and proteins able to interact with them. PIF are a family of bHLH TF able to bind directly to G-BOX in DNA; HY5 is a nuclear constitutive TF; BZR1 is a TF able to bind to PIF4 during brassinosteroids effect on photomorphogenesis; CIB is a bHLH TF that specifically controls Flowering Time locus; MYC2 is a bHLH TF in Arabidopsis; DELLA are proteins that interacts with PIF; COP1 is a ring finger ubiquitin that promotes HY5 degradation; HFR1 is a protein able to interact with PIF or BBX2, a zinc fingers proteins able to repress or modulate the action of transcription factors. The remaining factors are more specific of the plant hormones or the photoreceptor signaling pathways. ه Denotes participation in reproductive events (i.e., flowering). Details on how they interact can be found in the original references $\left({ }^{1} \mathrm{X} u\right.$ et al., $2014 ;{ }^{2} \mathrm{Lau}$ and Deng, 2010; ${ }^{3}$ Gupta et al., 2012; ${ }^{4}$ Liu et al., 2013; ${ }^{5}$ Fernando and Coupland, 2012; 6 Zhong et al., 2012; ${ }^{7}$ Alabadí and Blázquez, 2009; ${ }^{8}$ Hohm et al., $2013 ;{ }^{9}$ Jaillais and Grégory, 2012). ? Denotes pending confirmation.

The same wide genome approach has recently been used to report the genome and gene annotation of the edible carrageenophyte alga Chondrus crispus, the Irish moss (Collén et al., 2013). An important scientific background of knowledge exists for $C$. crispus, to the extent that it has been proposed as the model red alga (Collén et al., 2014). The 9,606 genes annotated for C. crispus have produced a very useful bulk of information for the interpretation of the forces driving the evolution of eukaryotic genomes (Collén et al., 2013). Interestingly, C. crispus has cryptochromes (Collén et al., 2013), which are important in photosensing and the regulation of the reproduction by light and hormones, as discussed below (Table 1). The phases of the life cycle of C. crispus are easily accessible and thus frequently used for experiments, but they might be not so easy to handle if the completion of the life cycle is required, as is the case for reproduction studies, for which mutants are required. Moreover, there is an apparent absence or shortage of well-known key elements in the regulatory network (i.e., absence of phytochromes, phototropins, and a rather small amount of transcription-associated proteins). Therefore, the utility of $C$. crispus as a model species for the study of certain aspects of algal growth and development during life cycle completion (i.e., light control of reproduction) remains a matter for debate.

Analysis of the transcriptomes has revealed preferential genes expressed in gametophytes or sporophytes. In Porphyra purpurea, an unusual elongation factor (EF-1a) was expressed only in the sporophyte while a second gene, EF, was expressed equally in the sporophyte and the gametophyte (Liu et al., 1996). The PyKPAl gene, which encoded a sodium pump, was differentially expressed in the gametophyte as compared to the sporophyte, which seems to depend on the presence of specific promoter elements (Uji et al., 2012, 2013). Apart from Porphyra/Pyropia, other species also considered to be of economic interest, such as the agarophytic species, have been studied. In this regard, carposporophyte-specific genes were identified in Gracilariopsis andersonii (Kamiya et al., 2011). In Gracilaria lemaneiformis, a female gametophyte-specific gene, GMF-01, has been reported (Chen et al., 2011) while an ubiquitin gene was also characterized as particularly active during the carposporophyte formation (Ren et al., 2009). In Griffithsia japonica, the GjFP-1 gene, encoding a heat-shock protein 90, may be involved in the differentiation of female gametophyte (Lee et al., 1998).

Other approaches have made it possible to reach candidate gene(s) involved in reproduction. This is the case of the GiODC gene in Grateloupia imbricata, which encodes the ornithine decarboxylase (ODC, EC. 4.1.1.17). The ODC starts the synthesis of the common polyamines putrescine, spermidine, and spermine by decarboxylating the ornithine to produce putrescine; these substances affect spore maturation and liberation as described below (García-Jiménez et al., 1998; Marián et al., 2000; GuzmanUrióstegui et al., 2002, 2012; Sacramento et al., 2004, 2007). GiODC was cloned using a somewhat laborious approach by means of degenerated primers designed from conserved protein motifs, followed by chromosome walking by iPCR to complete the sequence (García-Jiménez et al., 2009). GiODC expression varied according to cystocarp differentiation with lower levels in the fertile, as compared to the infertile, tissue (García-Jiménez et al., 2009).

All of these findings are clearly contributing to our knowledge about reproduction in red seaweeds, whether achieved through a wide genome strategy using high throughput methods as done in Porphyra/Pyropia or Chondrus, or using a candidate gene approach as in the case of ODC in Grateloupia imbricata. Nevertheless, the weakest point still remains on how this-perhaps species-specific-information can be translated into data that is relevant to most red seaweeds; how to construct a reliable "red seaweed conceptual framework" of knowledge on reproduction from these disparate approaches and species strategies. From our point of view this could only be started to achieve using a species that is easy to handle, with relatively short generation times, and fulfills the criteria needed to undergo genetic transformation, 
which constitutes the current bottleneck in the molecular biology of seaweeds (see Mikami, 2014).

\section{LIGHT AND PLANT HORMONES SIGNALING AND INTERACTION. THE WAY TO UNVEIL THE MOLECULAR SECRETS OF RED ALGAL REPRODUCTION?}

In photosynthetic eukaryotes, like algae, light is the driving force for growth and development; it is the source of energy, but also the signal triggering both vegetative and reproductive developmental events. Light is perceived through families of photoreceptors: phytochromes (red/far red radiation), UVR8 (UV-B), and membrane associated phototropins, cryptochromes, and the members of the ZTL/FKF1/LKP2 family which absorb UV-A/blue light (Hohm et al., 2013 and references therein). In turn, the existence and the type of photoreceptors in aquatic organisms have attracted scientific attention, due to the peculiar characteristics of the interaction of light in the aquatic environment. Thus, the presence of diverse genuine photoreceptors, such as phototropins, aurochromes (blue absorbing), neochromes - a kind of chimeric phytochrome, cryptochromes, and phytochromes in marine algae has been reported and reviews have been produced, which include future applied dimensions (Kianianmomeni and Hallmann, 2014). Interestingly, as far as signal transduction is concerned, the phototropin mechanism seems to be conserved between algae and higher plant (Huang et al., 2002; Onodera et al., 2005; Prochnik et al., 2010).

In seaweeds, plant hormones have been reported to affect growth and development (Chan et al., 2006; Baweja et al., 2009). Concerning reproduction events, in Grateloupia imbricata (as G. doryphora), the levels of the polyamines putrescine, spermidine, and spermine changed as the cystocarps maturate. Subsequently, it was observed that these polyamines, particularly spermine, favored the maturation, liberation, and growth of carpospores in Grateloupia imbricata and Hydropuntia cornea (as Gracilaria cornea; García-Jiménez et al., 1998; Marián et al., 2000; GuzmanUrióstegui et al., 2002, 2012; Sacramento et al., 2004, 2007). In addition, ethylene has been reported to accelerate the maturation of tetrasporangia in Pterocladiella capillacea (García-Jiménez and Robaina, 2012)

In recent years extensive knowledge has been accumulated about light, photoreceptors and plant hormone interaction, and crosstalk at the molecular level in higher plants, particularly during the events occurring at two physiological scenarios: seedling photomorphogenesis and shade avoidance (Gyula et al., 2003; Lau and Deng, 2010). Transcription factors of several families, protein-protein interaction, as well as post-translational protein modification are involved (Alabadí and Blázquez, 2009; Lau and Deng, 2010; Fernando and Coupland, 2012; Gupta et al., 2012; Jaillais and Grégory, 2012; Zhong et al., 2012; Liu et al., 2013). Table 1 provides an overview of the complex system operating in the light-photoreceptors-plant hormones integrated network. All of this important information has so far proved to be relevant to higher plants, particularly for the model species Arabidopsis thaliana, and it is completely unknown whether the key elements highlighted also operate in seaweeds, despite the fact that the influence of photoreceptors and plant hormones on reproduction has been reported, as previously mentioned.

Transcription factors controlled by photoreceptors, such as the PIF family (Alabadí and Blázquez, 2009; Lau and Deng, 2010; Jaillais and Grégory, 2012; Zhong et al., 2012), along with others under the control of plant hormones, such as HY5 (Lau and Deng, 2010; Xu et al., 2014), are very important players in the integrated network (Table 1). Other factors affecting plant growth and development, like circadian clock sensors that control endogenous levels of plant hormones (i.e., auxin), or temperature also seem to act by modulating the activity of PIF transcription factors, thus connecting important abiotic factors and development (Leivar and Quail, 2011).

Finally, by way of future perspective, in our laboratory we have recently adopted Bonnemaisonia hamifera (Bonnemaisoniaceae) as a working species. Cultures of the sporophyte (Trailliella) phase have been established so far, and work is progressing toward the induction of the differentiation of gametophytes, using temperature and photoperiod, and plant hormones (Figures 1A-C). Should the completion of the life cycle may be accomplished in the next future as a basic requirement for a working species, it remains to find an appropriate genomic structure (a compact or simple genome, a small number of genes, important functional transcriptomic information, etc.), but there is little information on the B. hamifera genome so far. Nevertheless, even in the long run, with $B$. hamifera or any other similar and more adequate species, it is time to revisit this scenario in seaweeds but focusing on the molecular standpoint; why not start identifying within the rising genomic/transcriptomic data for all or any of these regulating factors shown in Table 1 ?

\section{ACKNOWLEDGMENT}

The authors want to thank the support obtained from the Spanish Ministerio de Economía y Competitividad (Plan Nacional, grants \# BFU2003-01244; 2006-06918; 2010-17248).

\section{REFERENCES}

Agrawal, S. C. (2012). Factors controlling induction of reproduction in algae. Folia Microbiol. 57, 387-407. doi: 10.1007/s12223-012-0147-0

Alabadí, D., and Blázquez, M. A. (2009). Molecular interaction between light and hormone signalling to control plant growth. Plant Mol. Biol. 69, 409-417. doi: 10.1007/s11103-008-9400-y

Arun, A., Peters, N. T., Scornet, D., Peters, A. F., Mark Cock, J., and Coelho, S. M. (2013). Non-cell autonomous regulation of life cycle transitions in the model brown alga Ectocarpus. New Phytol. 197, 503-510. doi: 10.1111/nph. 12007

Baweja, P., Sahoo, D., García-Jiménez, P., and Robaina, R. R. (2009). Seaweed tissue culture as applied to biotechnology: problems, achievements and prospects. Phycol. Res. 57, 45-58. doi: 10.1111/j.1440-1835.2008.00520.x

Bornette, G., and Puijalon, S. (2011). Response of aquatic plants to abiotic factors: a review. Aquat. Sci. 73, 1-14. doi: 10.1007/s00027-010-0162-7

Chan, C. X., Blouin, N. A., Zhuang, Y., Zäuner, S., Prochnik, S. E., Lindquist, E., et al. (2012). Porphyra (Bangiophyceae) transcriptomes provide insights into red algal development and metabolism. J. Phycol. 48, 1328-1342. doi: 10.1111/j.1529-8817.2012.01229.x

Chan, C. Y., Ho, C., and Phang, S. M. (2006). Trends in seaweed research. Trends Plant Sci. 11, 165-166. doi: 10.1016/j.tplants.2006.02.003

Chen, P., Shao, H., and Xu, D. (2011). Cloning and characterization of a female gametophyte-specific gene in Gracilaria lemaneiformis (Gracilariales, Rhodophyte). Afr. J. Microbiol. Res. 5, 2590-2595. doi: 10.5897/AJMR11.133 
Cock, J. M., Sterck, L., Rouzé, P., Scornet, D., Allen, A. E., Amoutzias, G., et al. (2010). The Ectocarpus genome and the independent evolution of multicellularity in brown algae. Nature 465, 617-621. doi: 10.1038/nature09016

Coelho, S. M., Godfroy, O., Arun, A., Le Corguillé, G., Peters, A. F., and Cock, J. M. (2011). OUROBOROS is a master regulator of the gametophyte to sporophyte life cycle transition in the brown alga Ectocarpus. Proc. Natl. Acad. Sci. U.S.A. 108, 11518-11523. doi: 10.1073/pnas.1102274108

Cole, K. M., and Sheath, R. G. (1995). Biology of the Red Seaweeds. New York: Cambridge University Press.

Collén, J., Cornish, M. L., Craigie, J., Ficko-Bean, E., Hervé, C., Krueger-Hadfield, S. A., et al. (2014). "Chondrus crispus. A present and historical model organism for red seaweeds," in Advances in Botanical Research, Vol. 71, Sea Plants, ed. N. Bourgougnon (London: Elsevier), 53-89.

Collén, J., Porcel, B., Carré, W., Ball, S. G., Chaparro, C., Tonon, T., et al. (2013). Genome structure and metabolic features in the red seaweed Chondrus crispus shed light on evolution of the Archaeplastida. Proc. Natl. Acad. Sci. U.S.A. 26, 5247-5252. doi: 10.1073/pnas.1221259110

Drew, K. M. (1949). Conchocelis-phase in the life-history of Porphyra umbilicalis (L.) Kutz. Nature 164, 748-749. doi: 10.1038/164748a0

Drew, K. M. (1954). Life-history of Porphyra. Nature 173, 1243-1244. doi: 10.1038/1731243a0

Dring, M. J. (1988). Photo control of development in algae. Annu. Rev. Plant Physiol. Plant Mol. Biol. 39, 157-174. doi: 10.1146/annurev.pp.39.060188.001105

Fernando, A., and Coupland, G. (2012). The genetic basis of flowering responses to seasonal cues. Nat. Rev. Genet. 9, 627-639. doi: 10.1038/nrg3291

García-Jiménez, P., García-Maroto, F., Garrido-Cárdenas, J. A., Ferrandiz, C., and Robaina, R. R. (2009). Differential expression of the ornithine decarboxylase gene during carposporogenesis in the thallus of the red seaweed Grateloupia imbricata (Halymeniaceae). J. Plant Physiol. 166, 1745-1754. doi: 10.1016/j.jplph.2009.04.018

García-Jiménez, P., and Robaina, R. R. (2012). Effects of ethylene on tetrasporogenesis in Pterocladiella capillacea (Rhodophyta). J. Phycol. 48, 710-715. doi: 10.1111/j.1529-8817.2012.01156.x

García-Jiménez, P., Rodrigo, M., and Robaina, R. R. (1998). Influence of plant growth regulators, polyamines and glycerol interaction on growth and morphogenesis in carposporeling of Grateloupia doryphora cultured in vitro. J. Appl. Phycol. 10, 95-100. doi: 10.1023/A:1008063532233

Gupta, N., Prassad, V. B. R., and Chattopadhyay, S. (2012). LeMYC2 acts as a negative regulator of blue light mediated photomorphogenic growth, and promotes the growth of adult tomato plants. BMC Plant Biol. 14:38. doi: 10.1186/1471-2229-14-38

Guzman-Urióstegui, A., García-Jiménez, P., Marián, F., Robledo, D., and Robaina, R. (2002). Polyamines influence maturation in reproductive structures of Gracilaria cornea (Gracilariales, Rhodophyta). J. Phycol. 38, 1169-1175. doi: 10.1046/j.1529-8817.2002.01202.x

Guzman-Urióstegui, A., Robaina, R. R., Freile-Pelegri, Y., and Robledo, D. (2012). Polyamines increase carpospore output and growth during in vitro cultivation of Hydropuntia cornea. Biotechnol. Lett. 34, 755-761. doi: 10.1007/s10529-0110823-1

Gyula, P., Schäfer, E., and Nagy, F. (2003). Light perception and signalling in higher plants. Curr. Opin. Plant Biol. 6, 446-452. doi: 10.1016/S1369-5266(03) 00082-7

Hohm, T., Preuten, T., and Fankhauser, C. H. (2013). Phototropism: translating light into directional growth. Am. J. Bot. 100, 47-59. doi: 10.3732/ajb. 1200299

Huang, K. Y., Merkle, T., and Beck, C. F. (2002). Isolation and characterization of a Chlamydomonas gene that encodes a putative blue-light photoreceptor of the phototropin family. Physiol. Plant. 115, 613-622. doi: 10.1034/j.13993054.2002.1150416.x

Jaillais, Y., and Grégory, V. (2012). Brassinosteroids, gibberellins and light-mediated signalling are the three-way controls of plant sprouting. Nat. Cell Biol. 8, 788790. doi: $10.1038 /$ ncb2551

Kamiya, M., Kawai, H., Moon, D., and Goff, L. J. (2011). Isolation and characterization of phase-specific cDNAs from carposporophytes of Gracilariopsis andersonii (Gracilariales, Rhodophyta). Eur. J. Phycol. 46, 27-35. doi: 10.1080/09670262.2010.548101

Kianianmomeni, A., and Hallmann, A. (2014). Algal photoreceptors: in vivo functions and potential applications. Planta 293, 1-26. doi: 10.1007/s00425013-1962-5
Lau, O. S., and Deng, X. W. (2010). Plant hormone signalling lightens up: integrators of light and hormones. Curr. Opin. Plan Biol. 13, 571-577. doi: 10.1016/j.pbi.2010.07.001

Le Bail, A., Billoud, B., Le Panse, S., Chenivesse, S., and Charrier, B. (2011). ETOILE regulates developmental patterning in the filamentous brown alga Ectocarpus siliculosus. Plant Cell 23, 1666-1678. doi: 10.1105/tpc.110.081919

Lee, Y. K., Kim, S. H., Hong, C. B., Chah, O.-K., Kim, G. H., and Lee, I. K. (1998). Heat-shock protein 90 may be involved in differentiation of the female gametophytes in Griffithsia japonica (Ceramiales, Rhodophyta). J. Phycol. 34, 1017-1023. doi: 10.1046/j.1529-8817.1998.341017.x

Leivar, P., and Quail, P. H. (2011). PIFs: pivotal component in a cellular signalling hub. Trends Plant Sci. 16, 19-28. doi: 10.1016/j.tplants.2010.08.003

Liu, Q. Y., Baldauf, S. L., and Reith, M. E. (1996). Elongation factor 1 alpha genes of the red alga Porphyra purpurea include a novel, developmentally specialized variant. Plant Mol. Biol. 31, 77-85. doi: 10.1007/BF00020608

Liu, Y., Li, X., Li, K., Liu, H., and Lin, C. (2013). Multiple bHLH proteins form heterodimers to mediate CRY2-dependent regulation of flowering-time in Arabidopsis. PLoS Genet. 9:e1003861. doi: 10.1371/journal.pgen.1003861

Marián, F. D., García-Jiménez, P., and Robaina, R. R. (2000). Polyamine in marine macroalgae: natural levels of putrescine, spermidine and spermine in the thalli and change of their concentration during glycerol-induced cell growth in vitro. Physiol. Plant. 110, 530-534. doi: 10.1111/j.1399-3054.2000.1100416.x

Mikami, K. (2014). A technical breakthrough close at hand: feasible approaches toward establishing a gene-targeting genetic transformation system in seaweeds. Front. Plant Sci. 5:498. doi: 10.3389/fpls.2014.00498

Nakamura, Y., Sasaki, N., Kobayashi, M., Ojima, N., Yasuike, M., Shigenobu, Y., et al. (2013). The first symbiont-free genome sequence of marine red alga, Susabi-nori (Pyropia yezoensis). PLoS ONE 8:e57122. doi: 10.1371/journal.pone.0057122

Onodera, A., Kong, S. G., Doi, M., Shimazaki, K., Christie, J., Mochizuki, N., et al. (2005). Phototropin from Chlamydomonas reinhardtii is functional in Arabidopsis thaliana. Plant Cell Physiol. 46, 367-374. doi: 10.1093/pcp/pci037

Peters, A. F., Marie, D., Scornet, D., Kloareg, B., and Cock, J. M. (2004). Proposal of Ectocarpus siliculosus (Ectocarpales, Phaeophyceae) as a model organism for brown algal genetics and genomics. J. Phycol. 40, 1079-1088. doi: 10.1111/j.1529-8817.2004.04058.x

Prochnik, S. E., Umen, J., Nedelcu, A. M., Hallmann, A., Miller, S. M., Nishii I., et al. (2010). Genomic analysis of organismal complexity in the multicellular green alga Volvox carteri. Science 329, 223-226. doi: 10.1126/science. 1188800

Rebours, C., Marinho-Soriano, E., Zertuche-González, J. A., Hayashi, L., Vásquez, J. A., Kradolfer, P., et al. (2014). Seaweeds: an opportunity for wealth and sustainable livelihood for coastal communities. J. Appl. Phycol. 26, 1939-1951. doi: 10.1007/s10811-014-0304-8

Ren, X., Sui, Z., Mao, Y., Zang, X., Xu, D., and Zhang, X. (2009). Cloning and characterization of two types of ubiquitin genes from Gracilariopsis lemaneiformis (Gracilariales, Rhodophyta). J. Appl. Phycol. 21, 273-278. doi: 10.1007/s10811008-9361-1

Sacramento, A. T., García-Jiménez, P., Alcázar, R., Tiburcio, A. F., and Robaina, R. R. (2004). Influence of polyamines on the sporulation of Grateloupia (Halymeniaceae, Rhodophyta). J. Phycol. 40, 887-894. doi: 10.1111/j.15298817.2004.03183.x

Sacramento, A. T., García-Jiménez, P., and Robaina, R. R. (2007). Spermine induces cystocarp development in marine alga. Plant Growth Regul. 53, 147-154. doi: 10.1007/s10725-007-9212-0

Sahoo, D., Tang, X., and Yarish, C. (2002). Porphyra-the economic seaweed as a new experimental system. Curr. Sci. 83, 1313-1316.

Shevlin, D. E., and Polanshek, A. R. (1978). Life history of Bonnemaisonia geniculata (Rhodophyta): a laboratory and field study. J. Phycol. 14, 282-289. doi: 10.1111/j.1529-8817.1978.tb00300.x

Sutherland, E. J., Lindstrom, S. C., Nelson, W. A., Brodie, J., and Lynch, D. J. M. (2011). A new look at an ancient order: generic revision of the Bangiales (Rhodophyta). J. Phycol. 47, 1131-1151. doi: 10.1111/j.1529-8817.2011.01052.x

Uji, T., Hirata, R., Mikami, K., Mizuta, H., and Saga, N. (2012). Molecular characterization and expression analysis of sodium pump genes in the marine red alga Porphyra yezoensis. Mol. Biol. Rep. 39, 7973-7980. doi: 10.1007/s11033012-1643-7

Uji, T., Mizuta, H., and Saga, N. (2013). Characterization of the sporophytepreferential gene promoter from the red alga Porphyra yezoensis using transient gene expression. Mar. Biotechnol. 15, 188-196. doi: 10.1007/s10126-012-9475-y 
Xu, D., Li, J., Gangappa, S. N., Hettiarachchi, C., Lin, F., Andersson, M. X., et al. (2014). Convergence of light and ABA signaling on the ABI5 promoter. PLoS Genet. 10:e1004197. doi: 10.1371/journal.pgen.1004197

Yoon, H. S., Hackett, J. D., Ciniglia, C., Pinto, G., and Bhattacharya, D. (2004). A molecular timeline for the origin of photosynthetic eukaryotes. Mol. Biol. Evol. 21, 809-818. doi: 10.1093/molbev/msh075

Zhong, S. H., Shi, H., Xue, C., Wang, L., Xi, Y., Li, J., et al. (2012). A molecular framework of light-controlled phytohormone action in Arabidopsis. Curr. Biol. 22, 1530-1535. doi: 10.1016/j.cub.2012.06.039

Conflict of Interest Statement: The authors declare that the research was conducted in the absence of any commercial or financial relationships that could be construed as a potential conflict of interest.
Received: 10 November 2014; accepted: 04 February 2015; published online: 23 February 2015.

Citation: García-Jiménez P and Robaina RR (2015) On reproduction in red algae: further research needed at the molecular level. Front. Plant Sci. 6:93. doi: 10.3389/fpls.2015.00093

This article was submitted to Plant Evolution and Development, a section of the journal Frontiers in Plant Science.

Copyright (c) 2015 Garcia-Jiménez and Robaina. This is an open-access article distributed under the terms of the Creative Commons Attribution License (CC BY). The use, distribution or reproduction in other forums is permitted, provided the original author(s) or licensor are credited and that the original publication in this journal is cited, in accordance with accepted academic practice. No use, distribution or reproduction is permitted which does not comply with these terms. 